DOE/NASA/20320-67

NASA TM-87181

NASA-TM-87181

19860007017

\title{
Description and Test Results of a Variable Speed, Constant Frequency Generating System
}

Frank J. Brady

National Aeronautics and Space Administration

Lewis Research Center

December 1985

Prepared for

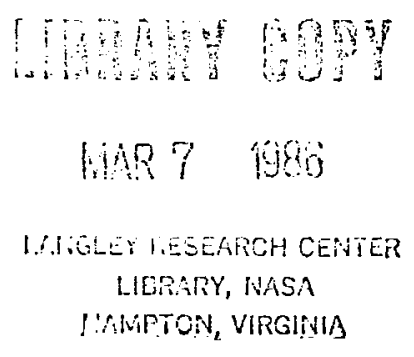

U.S. DEPARTIMENT OF ENERGY

Conservation and Renewable Energy Wind Energy Technology Division 


\section{DISCLAIMER}

This report was prepared as an account of work sponsored by an agency of the United States Government. Neither the United States Government nor any agency thereof, nor any of their employees, makes any warranty, express or implied, or assumes any legal liability or responsibility for the accuracy, completeness, or usefulness of any information, apparatus, product, or process disclosed, or represents that its use would not infringe privately owned rights. Reference herein to any specific commercial product, process, or service by trade name, trademark, manufacturer, or otherwise, does not necessarily constitute or imply its endorsement, recommendation, or favoring by the United States Government or any agency thereof. The views and opinions of authors expressed herein do not necessarily state or reflect those of the United States Government or any agency thereof.

Printed in the United States of America

Available from

National Technical Information Service

U.S. Department of Commerce

5285 Port Royal Road

Springfield, VA 22161

NTIS price codes 1

Printed copy:

Microfiche copy: A01

1 Codes are used for pricing all publications. The code is determined by the number of pages in the publication. Information pertaining to the pricing codes can be found in the current issues of the following publications, which are generally available in most libraries: Energy Research Abstracts (ERA); Government Reports Announcements and Index (GRA and I); Scientific and Technical Abstract Reports (STAR); and publication, NTIS-PR-360 available from NTIS at the above address. 
DOE/NASA/20320-67

NASA TM-87181

\section{Description and Test Results of a Variable Speed, Constant Frequency Generating System}

Frank J. Brady

National Aeronautics and Space Administration

Lewis Research Center

Cleveland, Ohio 44135

December 1985

Work performed for

U.S. DEPARTMENT OF ENERGY

Conservation and Renewable Energy

Wind Energy Technology Division

Washington, D.C. 20545

Under Interagency Agreement DE-AI01-76ET20320 
. 
DESCRIPTION AND TEST RESULTS OF A VARIABLE SPEED, CONSTANT FREQUENCY GENERATING SYSTEM

\author{
Frank J. Brady \\ National Aeronautics and Space Administration \\ Lewis Research Center \\ Cleveland, Ohio 44135
}

\begin{abstract}
SUMMARY
The variable-speed, constant frequency generating system developed for the Mod-0 wind turbine is presented. The development of this system occurred in several stages. This report describes the system as it existed at the conclusion of the project. The cycloconverter control circuit is described in deta11. The major addition to the control circuit, field-oriented control, is also described. Laboratory test and actual wind turbine test results are included.
\end{abstract}

\title{
INTRODUCTION
}

The Wind Energy Project Office has undertaken the development of a variable-speed, constant frequency (VSCF) generating system for use in the Mod-0 wind turbine at the Plum Brook Station. This project has been accomplished in several phases. The original system was designed by Ferber $R$. Schleif, a consulting engineer. The first phase was to test the system in its original form in the laboratory. The results of these test are presented in reference 1. The second phase of development consisted of modifying the original control circuit and repeating the laboratory tests in order to determine if the modifications had improved the performance. The third phase consisted of operating the VSCF system on a wind turbine. This paper will cover phase two in some detall and to a lesser degree the results of phase three.

The purpose of investigating a VSCF system was to demonstrate that it can improve the operations of a wind turbine. Improves in this case, means that the overall wind turbine functions more smoothly, efficiently, and reliably than with an active pitch control, a slip coupling, and a synchronous generator.

\section{DESCRIPTION OF THE SYSTEM}

The generator is a three-phase, wound-rotor induction machine. Its shaft rating is $250 \mathrm{hp}$, the stator voltage is $480 \mathrm{~V}$, the rotor voltage is $480 \mathrm{~V}$ at 50 percent slip, the synchronous speed is $1800 \mathrm{rpm}$, the speed range is 900 to $2700 \mathrm{rpm}$, and the ratio of rotor conductors per slot to stator conductors per slot is 2. The cycloconverter is a 12-pulse, noncirculating current type.

In the laboratory the generator is driven by a $400 \mathrm{hp}$, variable-speed dc motor that is armature controlled. All testing is done with this motor operating in a speed-regulating mode. Also, all testing is done with the stator of the generator connected to the utility network (an infinite bus) and with the 
rotor fed through the cycloconverter. Figure 1 shows the configuration of the system as it was tested.

The VSCF system was also tested on a wind turbine and typical strip chart recordings of its operation are included in this report. For these tests the wind turbine is operated in a fixed-pitch, fixed-yaw mode. The generator installed on the wind turbine is identical to the one used for the lab tests. However, the same cycloconverter is used for both the lab tests and the wind turbine tests.

The cycloconverter is the most important component in this system. More important, it is the control section of the cycloconverter that determines how well the variable speed system operates. Therefore, a functional description of the control circuit will be covered before any test results are presented.

\section{DESCRIPTION OF THE CYCLOCONVERTER}

The cycloconverter power section is a 3-phase, 12-pulse, noncirculating current type. Each phase consists of standard three-phase thyristor bridges, so that one pair of bridges supply the positive half cycle of load current; a second pair supplies the negative half cycle. Figure 2 is a one-line diagram of the power section.

The current shunts are important elements in this system because they provide two essential signals. One signal is current feedback which is needed to regulate rotor current. The other signal is a bridge enable, which is a logic signal that prevents one pair of bridges from being switched on while the other pair is conducting. That is, current in the positive shunt must be equal to zero before the thyristors in the negative bridge can be fired, and viceversa. The power section will not be described in any more detail since its design does not include any novel features. The control circuit, however, will be covered in more detail because it does incorporate some unusual features.

The objective of the cycloconverter control circuit in this variable speed constant frequency systems is to regulate the stator real power and reactive power for varying shaft speed over a range of speeds. Moreover, the circuit must control these powers with the generator stator connected to an infinite bus (that is, a power system whose voltage and frequency does not vary).

The operation of the control circuit can be broken down into four distinct areas as shown in figure 3 . The first block in figure 3 is a slip frequency generator. The purpose of this circuitry is to sense the speed of the generator and output a constant amplitude sinewave whose frequency is equal to slip frequency. That is, the difference between 1 ine frequency $(60 \mathrm{~Hz})$ and the mechanical frequency. The circuitry actually generates sine and cosine waves which are used to produce a three-phase system of control signals.

The field oriented control block takes the slip frequency signals and converts them to signals whose amplitude and phase are functions of the stator real and reactive powers. When the rotor current is precisely the correct slip frequency, then the rotor magnetic field is in synchronization with the stator magnetic field and the real and reactive powers are determined by the relative phase and amplitude of the two magnetic fields. Assuming the stator field is the reference, then the relative phase angle between the stator and the rotor 
is directiy related to the variation in phase of the rotor current. Therefore the purpose of this field oriented control circuitry is to vary the amplitude and phase of the rotor current, so that the rotor and stator magnetic fields maintain the desired relative orientation.

The purpose of the modulating signal error amplifier block in figure 3 is to regulate rotor current. The rotor of the generator must be supplied with relatively constant current at all slip frequencies and to achieve this, a current feedback loop is used.

The fourth block in figure 3 uses the error signal from the error amplifier to modulate the firing angle of the SCR's. As stated previously, the objective of the cycloconverter control circuit is to regulate the stator's real and reactive powers. In order to achleve this, the rotor current must be regulated in amplitude, frequency, and phase. The precision with which these three variables are regulated will determine the magnitude of the variations seen in the real and reactive stator powers.

We will now give a more detailed explanation of the circuitry within each block. As before, let's start with the slip frequency generator shown in more detall in figure 4. The quadrature sinewave oscillator generates two signals at a frequency $\left(f_{0}\right)$ of $2000 \mathrm{~Hz}$. A voltage controlled oscillator (VCO) operates at a frequency of $2000 \mathrm{~Hz}$ plus or minus the slip frequency $\left(\mathrm{f}_{0 \pm}+\mathrm{Sf}_{\mathrm{s}}\right)$, where $S=$ slip and $f_{S}=$ stator frequency $(60 \mathrm{~Hz})$. When the quadrature oscillator signal is sampled at the VCO frequency the output of the sample and hold module is two quadrature signals whose frequency is the siip frequency.

The slip frequency is controlled by the voltage at the input of the vco. Figure 4 shows that this input is the sum of three voltages. The phase error signal is a voltage proportional to the phase difference between the network voltage and the open-circuit voltage of the stator. The purpose of this input is to insure that the generator is synchronized at zero phase error. In other words, the open-circuit voltage of the stator is compared to the network voltage, the phase difference signal is fed to the VCO that in turn keeps the two voltages in phase. However, this signal becomes zero at the moment of synchronization and does not influence the dynamics of the system. The other two signals, speed and power error have a major influence of the operation of the system. Remember that for proper operation the rotor flux must stay in synchronization with the stator flux. It is the voltage input to the vco that determines how precisely synchronism is maintained. The speed signal determines the frequency of the VCO which in turn sets the slip frequency. This slip frequency generator drifts over time and the method that was used to compensate for this was to introduce the highly damped power error signal. This is the reason for the third input to the vco.

The next block in the cycloconverter in the field-oriented control circuit as shown in figure 5 . The purpose of this is to take the slip frequency waveform and convert it to a signal at the same frequency but whose phase angle can be modulated. The end result of this is that the rotor flux, in addition to being in synchronism with the stator flux, can also be made to lead or lag the stator flux. We now have two independent means of controlining the rotor flux. One is speed, which sets the slip frequency. The other, provided by the field oriented control the leading or lagging (the phase) of the flux. 
In the lower right-hand corner of figure 5 there is a phasor diagram which explains the purpose of this circuitry. In that diagram the sin $w_{S} t$ and $\cos w_{s} t$ are the input and are the reference phasors. We want to generate a new set of quadrature phasors ( $\phi 1$ and $\phi 2)$ whose phase and magnitude relation to the reference phasors can be independentiy controlled. Below the phasor diagram in figure 5 are the equations for $\phi 1$ and $\phi 2$. From the equations it can be seen that the magnitude and phase of $\phi 1$ and $\phi 2$ is determined by the quantities, $A$ and $B$. The quantities $A$ and $B$ are determined by the power and var error signals. The derivation of the equations that define $A$ and $B$ is not part of the paper. They are derived from a mathematical model developed in references 2 and 3 . Finally, the quadrature system of control signals is converted to a three-phase system of signals that will be used to modulate the firing angle of the SCR's in the power section of the cycloconverter.

The circuit development up to this point can be summarized as follows: The slip frequency circuit and the field-oriented circuit generates a threephase system of control voltages whose frequency is equal to the slip and whose phase and magnitude are a function of the stator power and stator vars.

The three control signals that emerge from the two-phase to three-phase conversion will be used to modulate the firing angles of the SCR's in their respective phase of the rotor. However the firing angles are modulated with an error signal. Because the rotor must be excited with relatively constant current at all rotor frquencies, the loop is closed on rotor current at this point. The rotor current feedback signal is summed with the modulating voltage signal to produce a modulating error signal as shown in figure 6 . There is an error signal generated for each positive and each negative bridge. The output waveform for each bridge is shown in figure 6 . The shaded part of the wave is the portion that is producing rotor current. The circuit has two additional features that are shown in figure 6 . The residual angle adjustment sets a bias on the firing angle which, in turn, has the effect of setting the minimum value of rotor current. This, in turn, effects the smoothness of the zero transitions of the rotor current.

The other feature that the error amplifier circuit has is the diode clamp. The purpose of this is to limit the maximum firing angle. The clamp is bipolar in order to limit the firing angle in both the positive and negative current directions.

The final block in the cycloconverter control circuit is the gate pulse generation. The circuitry and waveforms are shown in figures $7(a)$ and (b). If this circuitry is viewed as a black box, there are two inputs and one output. The output is a pulse train that is fed to the gates of the SCR's. The pulse train is referenced to the waveform feeding the cycloconverter; however, the phase relation between the pulse train and the input waveform can be varied. Figure $7(a)$ shows that the input reference waveform is the $60 \mathrm{~Hz} 1$ ine-toline voltage at the cycloconverter's input. Figure $7(b)$ shows the firing angle modulation input which is the output from the previous circuitry. This modulation voltage varies the phase of the pulse train. The output current from the cycloconverter is in turn proportional to this modulation voltage.

For a more detailed explanation of this current refer to figure $7(a)$. This circuit generates two references, a delta and a wye sawtooth wave which are needed in a 12-pulse cycloconverter. The sawtooth waves, S1 and S2, are 
used as a reference for all the gate pulses in the delta system. Waveforms S3 and 54 are used as references in the wye system.

The input is the line to line voltage which is transformed down to signal level. The sinewave is delayed and converted to a squarewave. The falling edge of the square provides the trigger to the ramp generator. The sawtooth waveform, S2 is $180^{\circ}$ out of phase with S1. Sawteeth S3 and S4 1ag S1 and S2 by $30^{\circ}$.

In figure $7(b)$ the sawteeth are compared to a reference voltage level, the output of the comparator is a squarewave whose leading edge provides the trigger to the pulse shaping circuit. The output of the pulse shaper is a $50 \mu s e c$ pulse that is amplified and fed to the SCR gate.

The reference voltage on the comparators are set so that a set of 6 pulses are generated, each one being $60^{\circ}$ from the previous pulse. These pulses are moved leading or lagging their zero position by the modulation input. As the modulating voltage becomes negative the pulse lead their zero position, as the voltage becomes positive the pulse lag the zero position. The current output of the cycloconverter is proportional to the change in phase angle (firing ang (e).

A set of six pulses is fed to each bridge and each output phase of the cycloconverter has a positive and a negative bridge. In order to produce an ac wave from this configuration, the positive current wave is produced by the positive bridge while the negative current cycle is produced by the negative bridge. The logic signal that selects which bridge is in operation is the bridge enable signal. This signal is generated by sensing the current flowing in each bridge. When the current in one bridge is zero, then the other bridge is enabled.

In summary, the output current from the cycloconverter is an amplification of the signal that appears at the firing angle modulation input that is shown in figure $7(b)$. The frequency of this signal is determined by the sip frequency generator, while its amplitude and phase are determined by the fieldoriented control.

\section{LABORATORY TESTING}

This system was tested in the laboratory so that the present control scheme could be compared with the previous scheme. The testing results of the previous scheme. The testing results of the previous control scheme are documented in reference 1 .

The tests that were repeated are; (1) the response to a step change in the power command; (2) the response to a step change in the reactive power command; (3) the maximum power; and (4) the stator current spectrum.

Figure 8 shows the response to a step change in the power command, at three rotor speeds. When this data is compared with the same data in reference 1 , the dynamic (that $1 \mathrm{~s}$, the ringing and damping) appearance of the response has not changed. However, the power level at which the test can be performed has increased. That is, the maximum power step that could be used 
in the previous control configuration is a step from 50 to $100 \mathrm{~kW}$. With the new configuration, the system will tolerate a power step from 100 to $150 \mathrm{~kW}$.

Figure 9 shows the response to a step change in the reactive power command, at three rotor speeds. The nature of this response is similar to the response shown in reference 1, figure 9. The step change in the stator KVARS is more abrupt in the present system only because the reactive power feedback path has a wider bandwidth than was used in the previous configuration.

It was noted in reference 1 that the maximum power level that could be achieved with the previous controls was $130 \mathrm{~kW}$. If this level was exceeded, the system would become unstable. Using the present control scheme, the system can operate successfully at a power level of $175 \mathrm{~kW}$. However, if this level is exceeded this system will also become unstable.

The stator current spectra that resulted from the two control schemes is also very similar. Both spectra contain harmonics of the same integer multiples of $60 \mathrm{~Hz}$ and of the same amplitudes. The major difference between the two is that the spectrum from the present configuration has a higher level of background noise. The reason for this is attributed to the fact that the bandwidths of real and reactive power feedback paths have been increased. The previous bandwidth was $1 \mathrm{~Hz}$ while the present bandwidth is $100 \mathrm{~Hz}$.

There are some problems that still exist with this system. Sudden changes in rpm and power produce a response that is characterized as underdamped. The reason for this is, primarily, the delay in the speed feedback signal to the slip frequency generator. Specifically, it is the frequency-to-voltage (F/V) converter in this path that is producing the problem. A second major problem is that the operating speed range is limited because the cycloconverter cannot generate slip frequencles greater than $10 \mathrm{~Hz}$. The SCR's do not commutate properly at higher frequencies. The cause of the problem is not known.

\section{WIND TURBINE TESTING}

In order for the VSCF to operate successfully on the Plum Brook wind turbine only one control modification was necessary. The operation of the generator was limited to a speed range from 1500 to $2100 \mathrm{rpm}$, which in turn was dictated by the cycloconverter. In order to keep the machine in that speed range requires the generator loading to increase as the wind velocity increases. The available power increases as the cube of the wind velocity. If the generator load is not increased to compensate for the increase in input power, then the RPM of the system will increase. In practice, the increase in rpm occurs so rapidly that the operating speed range cannot be maintained. In order to keep the system operating within the speed range, the power command is programmed. Specificaliy, a circuit monitors the rpm and outputs a power command that is a linear function of speed.

One of the reasons for considering a VSCF system on a wind turbine is that it could replace an active pitch control system. To demonstrate this, the Plum Brook wind turbine was operated in this manner. The pitch was fixed as long as the speed of the wind turbine was within the operating range, 1500 to $2100 \mathrm{rpm}$. 
Figure 11 shows the system responding to a wind gust. The two sections of strip recording (covering the same period of time) show that the wind speed increased from approximately 6 to $12 \mathrm{mph}$, which in turn produced a speed increase from 1600 to $1700 \mathrm{rpm}$, and a power increase from 50 to $90 \mathrm{~kW}$. This system responded in a well behaved manner.

Figure 12 is included to show how the system operates near and at synchronous speed. The recording show that transitions through synchronous speed are well behaved. One of the concerns expressed by others, is that the cycloconverter would have to be designed for a dc current of the peak excitation if the machine operated at synchronous speed for extended periods. Due to the variable nature of the wind, the time spent at any one speed is very short. Therefore, the cycloconverter (in this application) would not have to meet this design requirement.

\section{CONCLUSION}

This particular VSCF design was built, modified, and tested. The testing showed that the cycloconverter has some deficiencies. Neglecting the shortcomings of this particular system, a VSCF generator has the potential to improve the overall operation and reliability of a wind turbine.

\section{REFERENCES}

1. Brady, F.J.: Laboratory Testing of a 200-kW Variable-Speed Generating System. Presented at the DOE/NASA Workshop on Horizontal-Axis Wind Turbine Technology (Cleveland, Ohio), May 8-10, 1984.

2. Brady, F.J.: A Mathematical Model for the Doubly Fed Wound Rotor Generator. NASA TM-83454, 1983.

3. Brady, F.J.: A Mathematical Model for the Doubly-Fed Wound Rotor Generator, Part II. NASA TM-83581, 1984. 


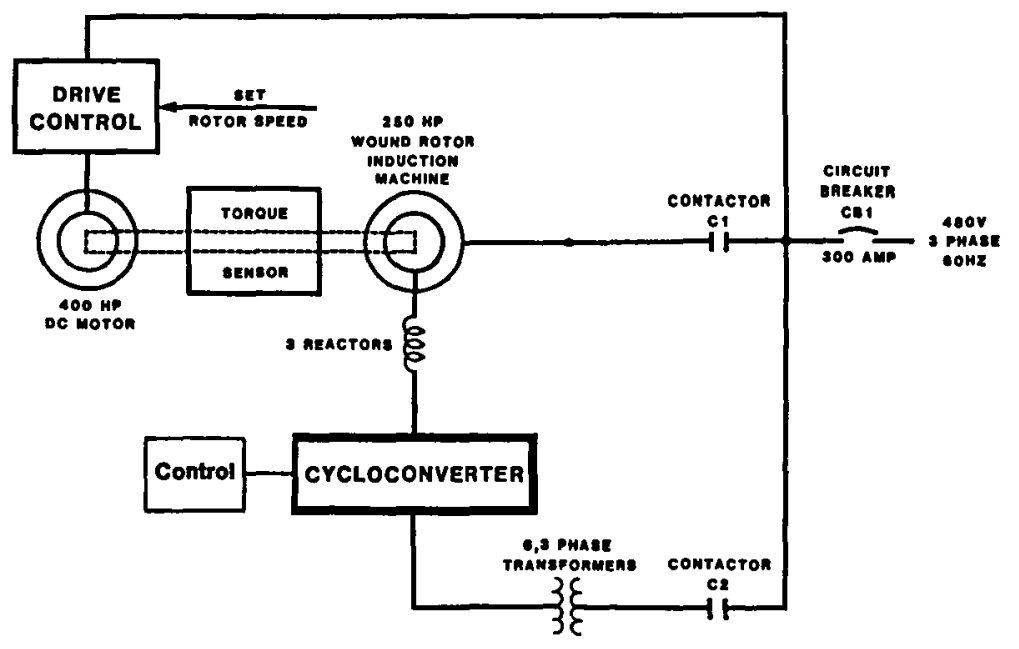

VARIABLE-SPEED CONSTANT FREQUENCY GENERATOR

LABORATORY TEST CONFIGURATION

FIGURE 1

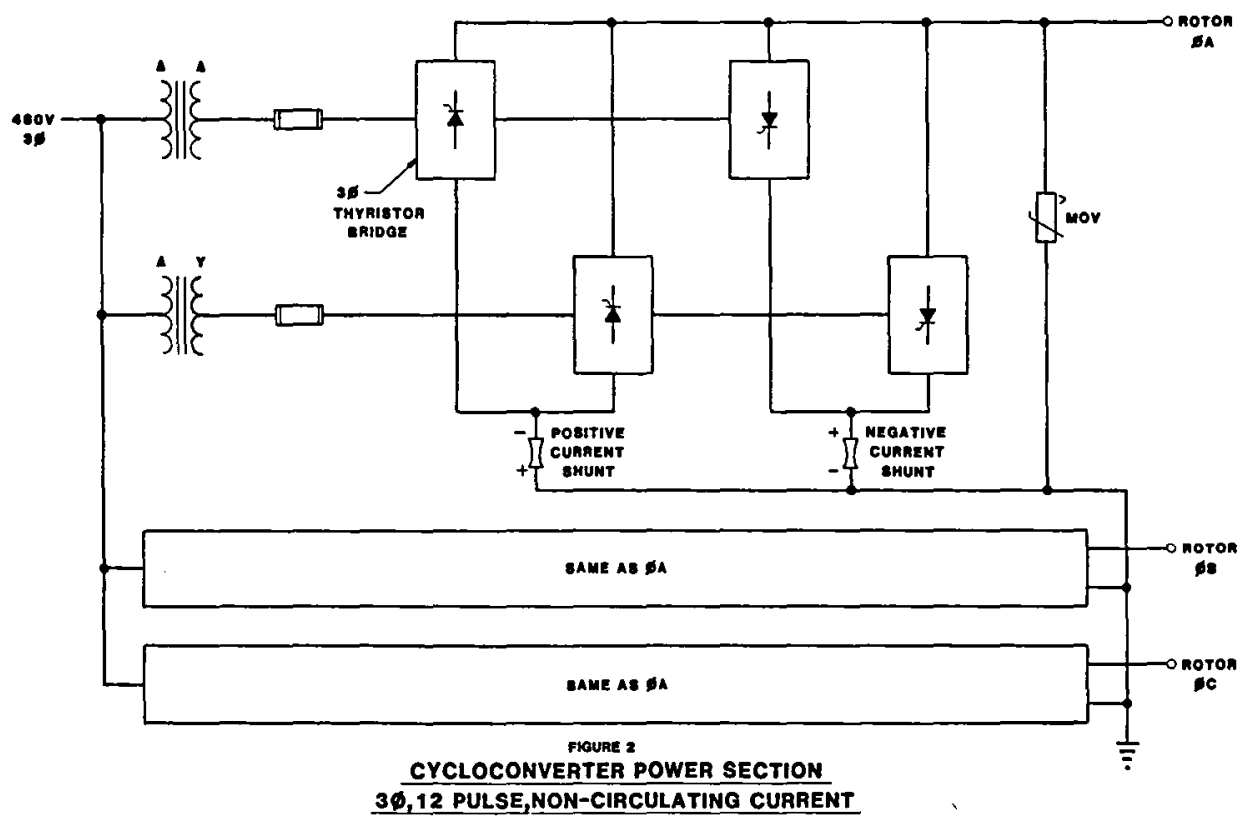



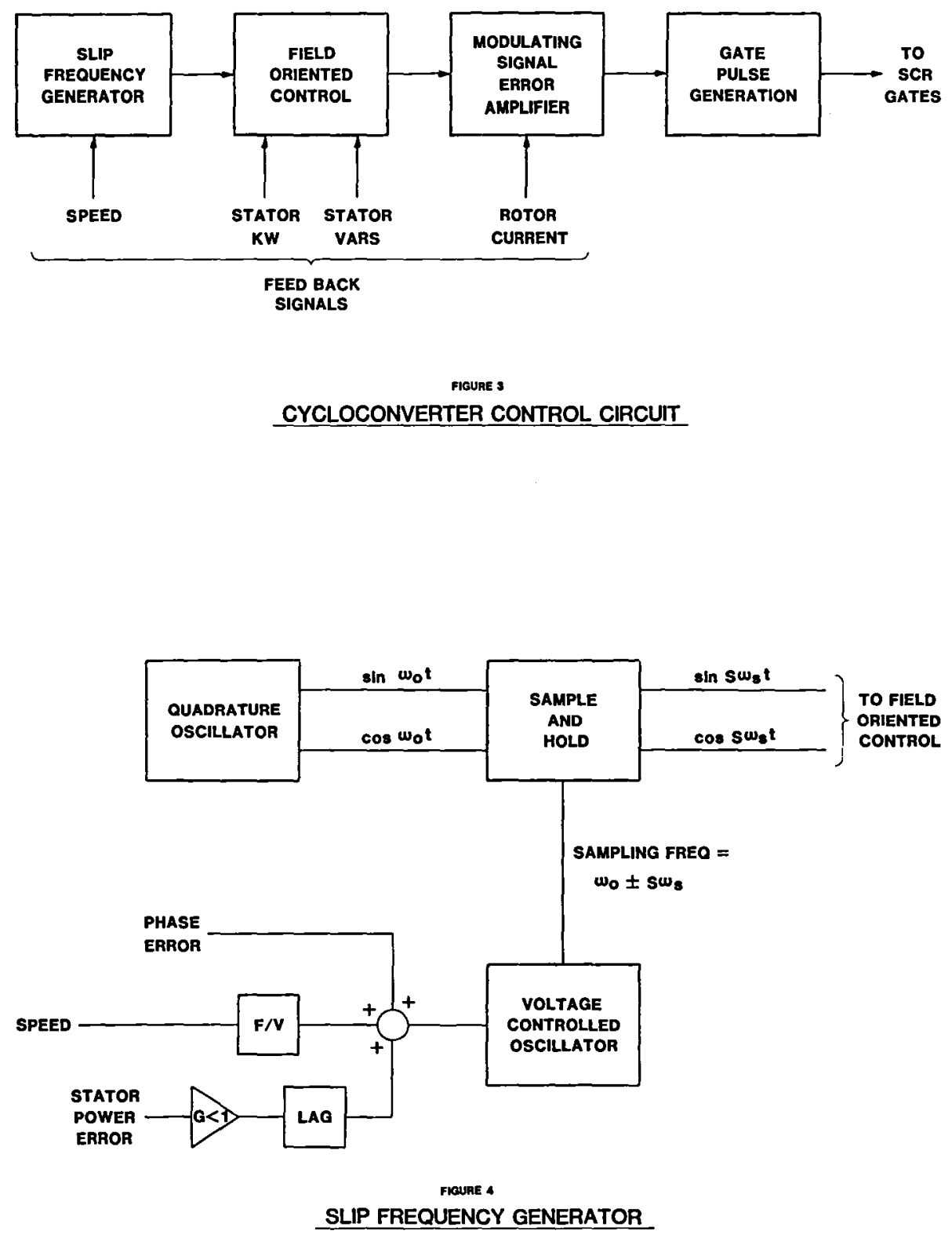

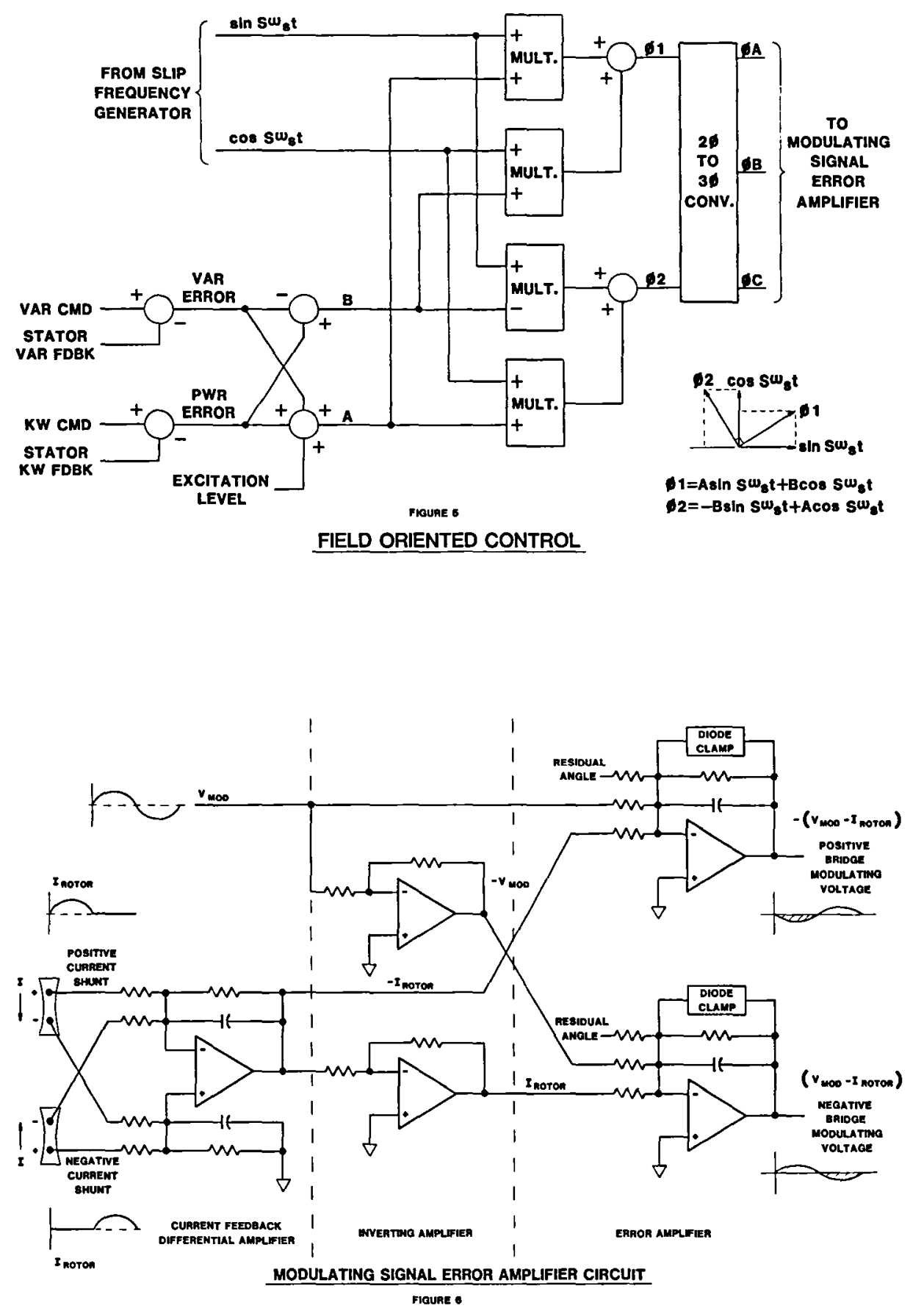


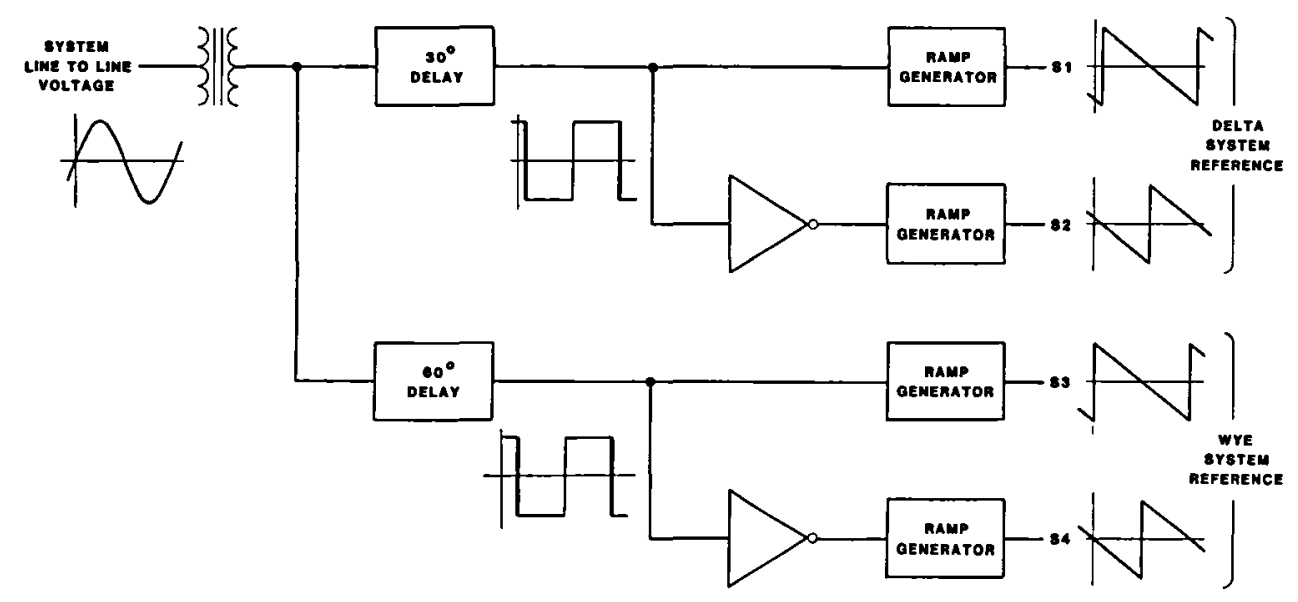

SAWTOOTH REFERENCE

FIGUAE $\mathrm{PA}$

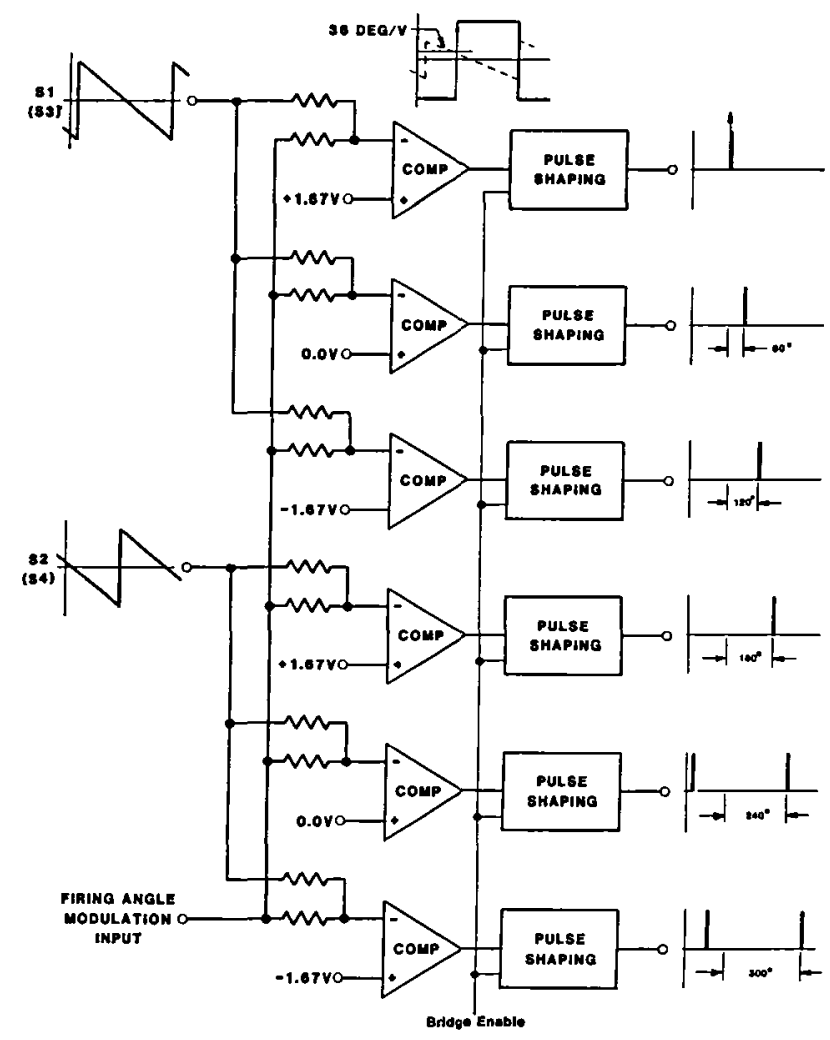

GATE PULSE TIMING 


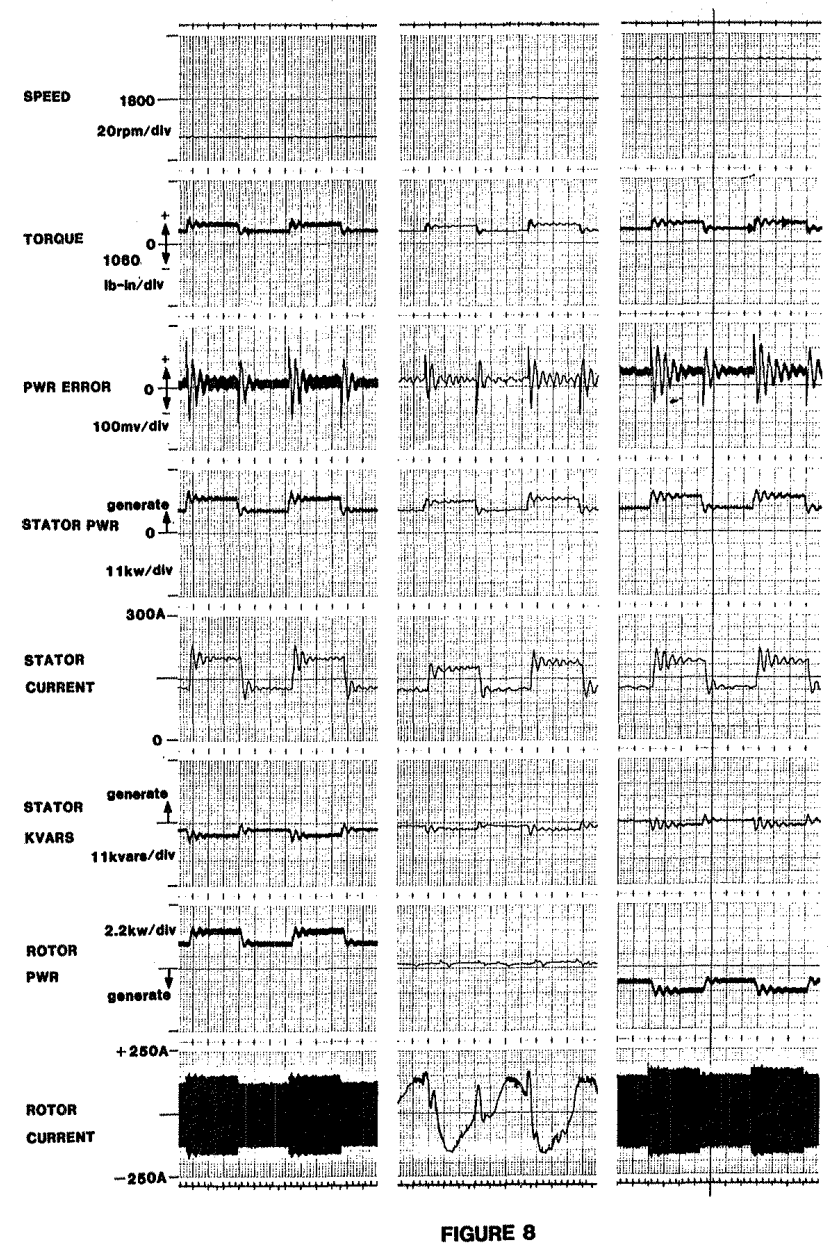




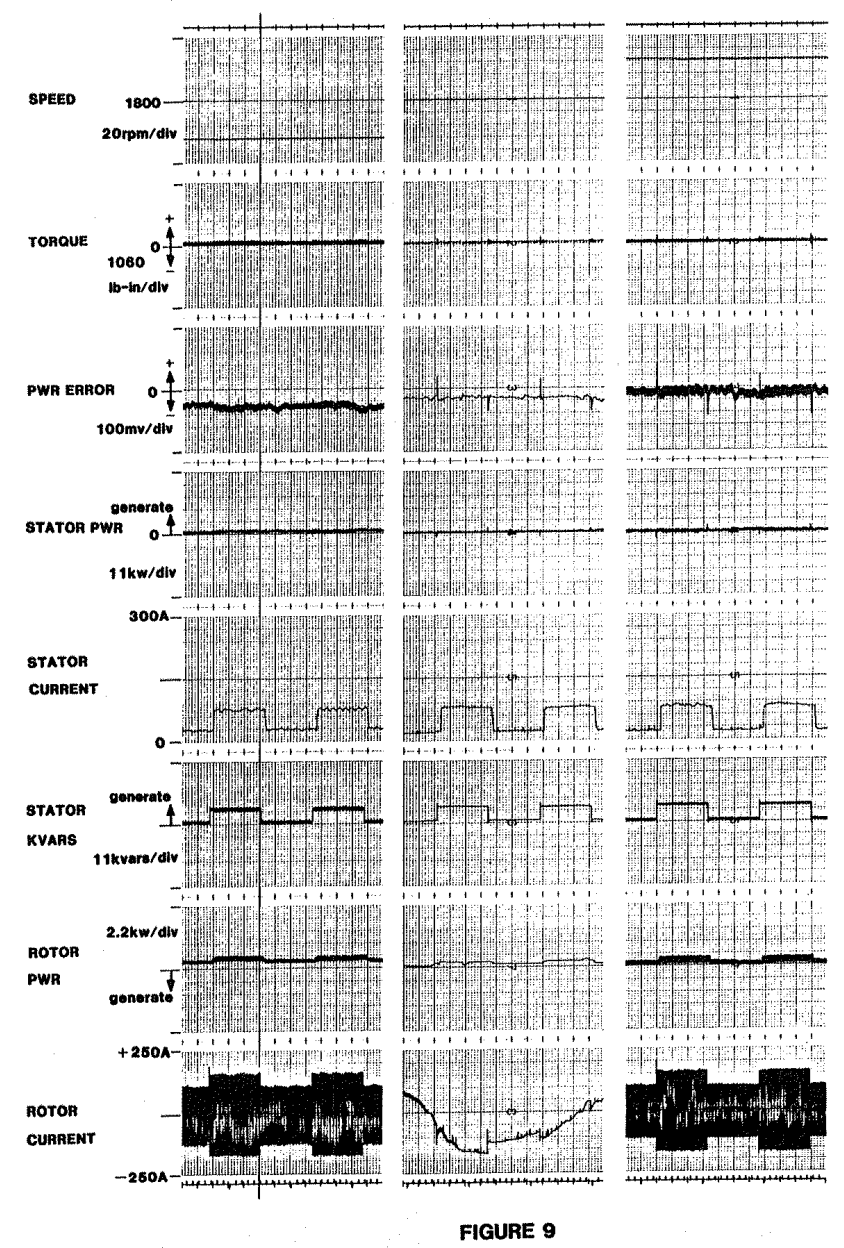




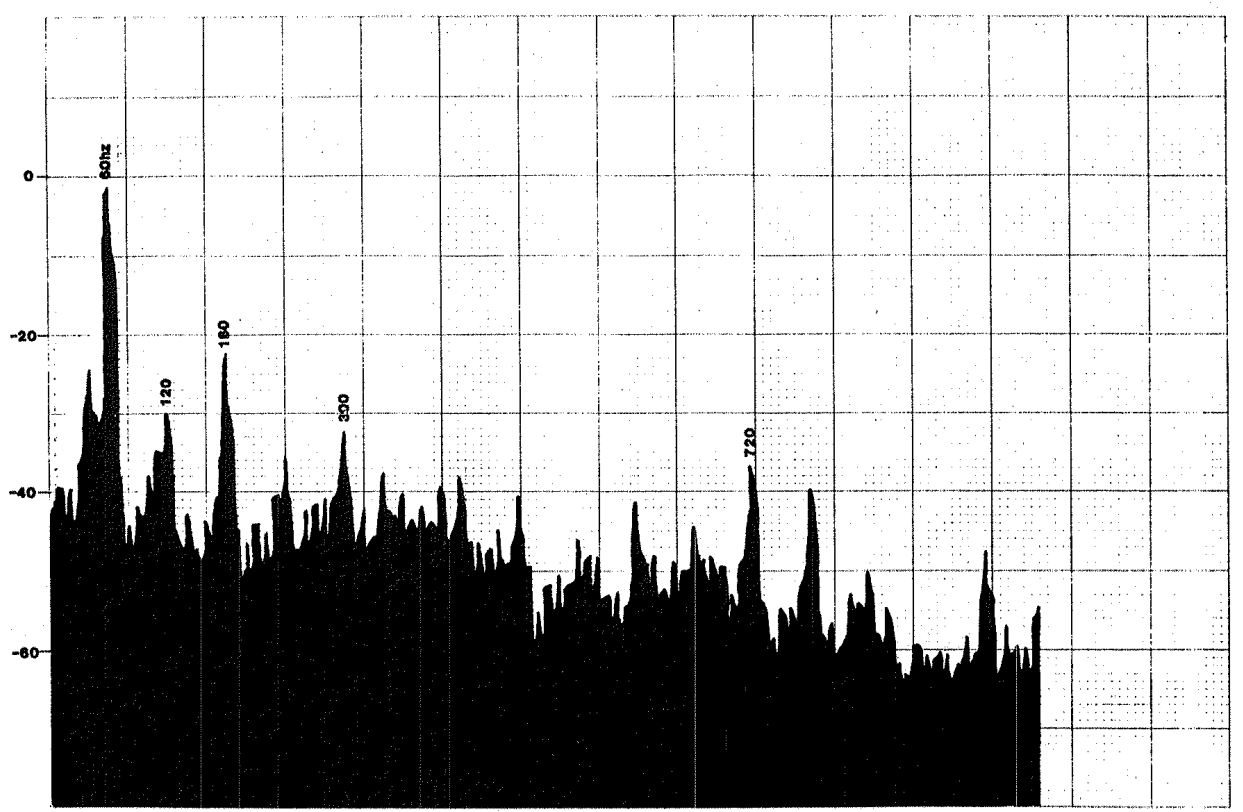

FIQURE 10. - Stator Curromt Spectra at 100KW,1.0PF,1500 rpm

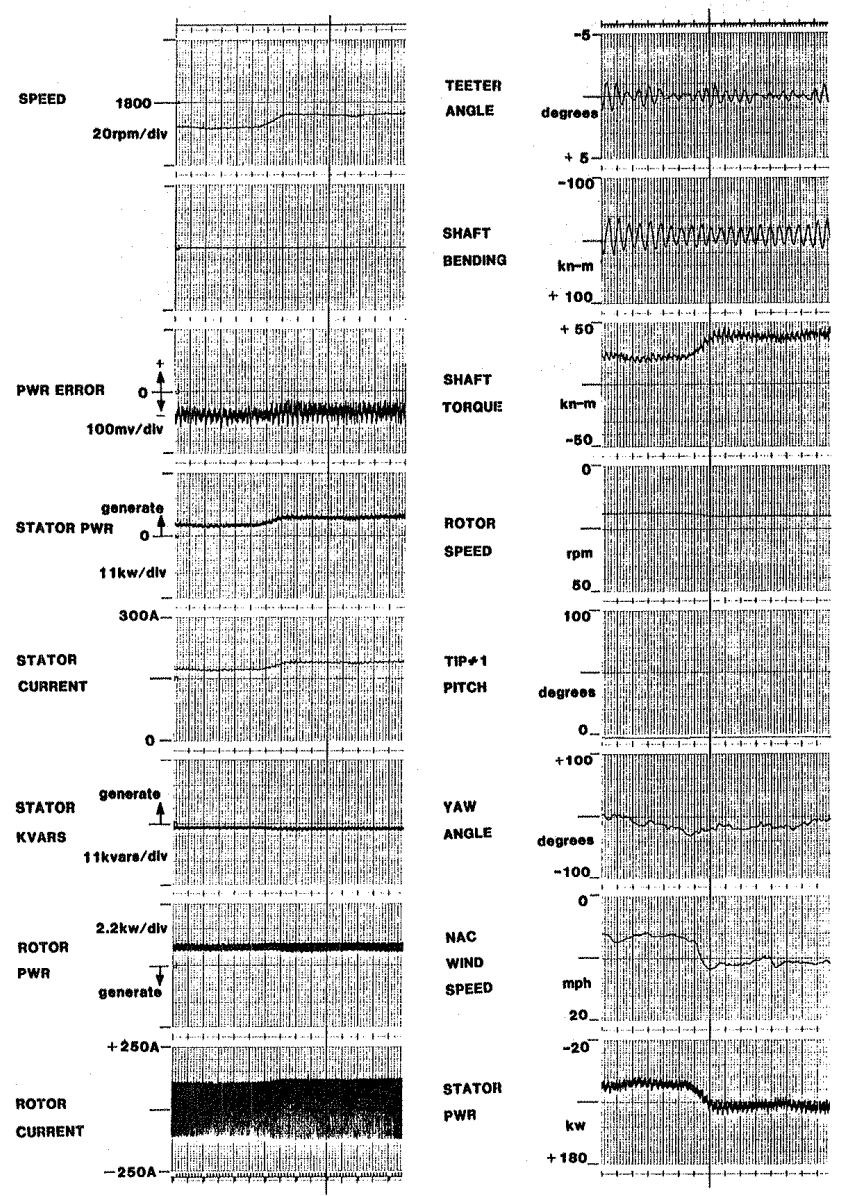

FIGURE 11 


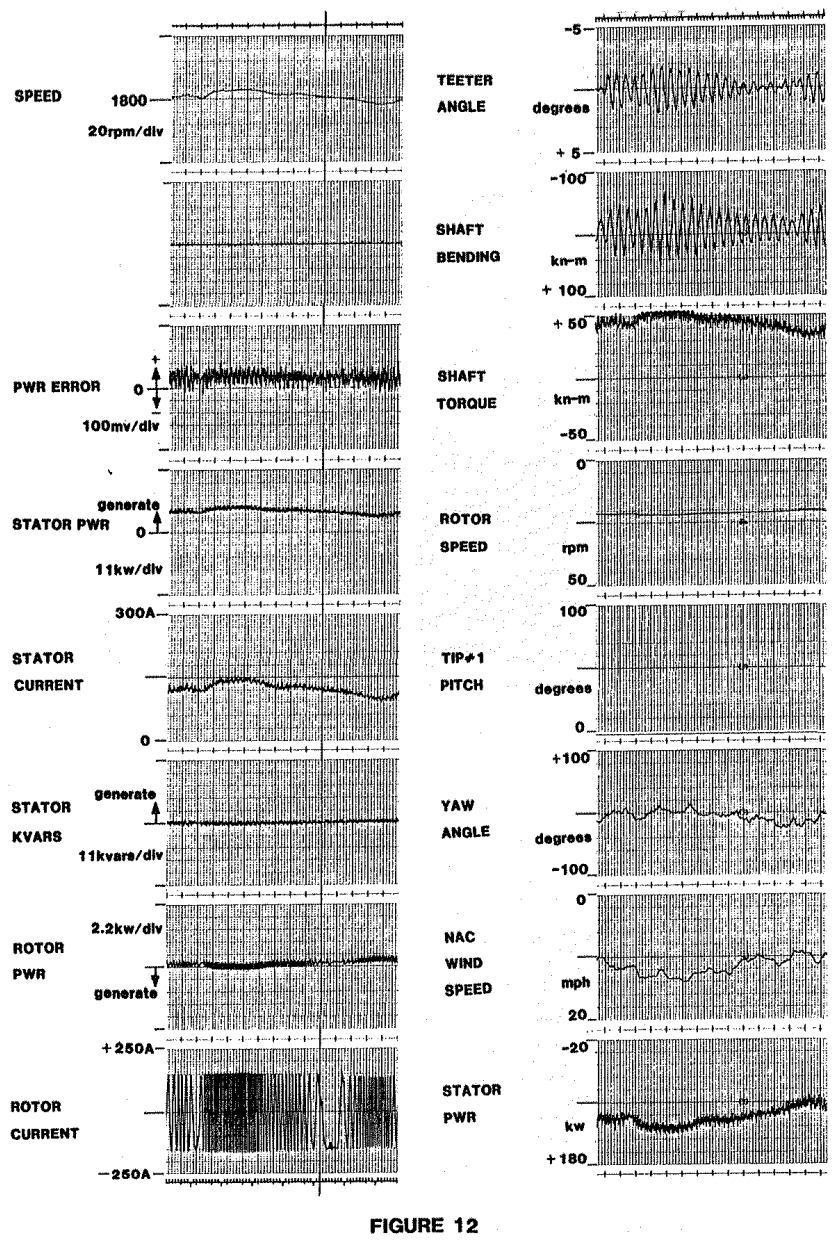




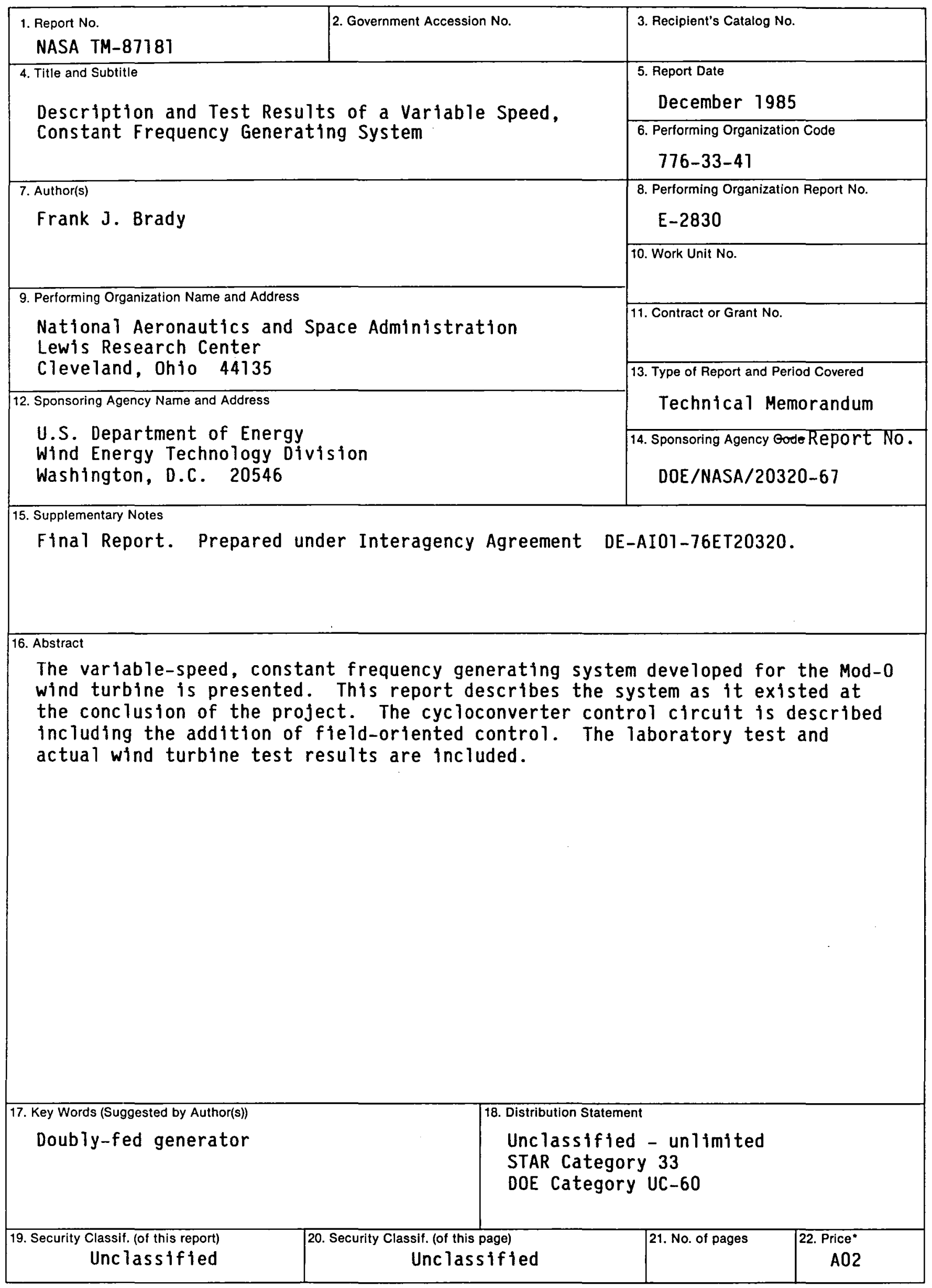


End of Document 